УДК 547.97

\title{
ОПТИМИЗАЦИЯ УСЛОВИЙ ЭКСТРАГИРОВАНИЯ АНТОЦИАНОВЫХ КРАСИТЕЛЕЙ ИЗ РАСТИТЕЛЬНОГО СЫРЬЯ
}

\author{
(ㄱ) И.В. Переверткина*, А.Д. Волков, Н.Н. Титова, В.М. Болотов \\ Воронежский государственный университет инженерных технологий,
пр. Революции, 19, Воронеж, 394000 (Россия), e-mail: pinna58@mail.ru
}

Для оптимизации условий экстрагирования антоциановых красителей из растительного сырья проведено исследование влияния на их степень извлечения и стабильность следующих параметров: сырья, растворителя, рН среды, температуры и времени. Определены условия, позволяющие повысить селективность экстракции красных пигментов, интенсифицировать процесс, упростить способ получения красителя. Данный краситель может быть использован для окраски продуктов питания с повышенной кислотностью, минуя стадии концентрирования, хранения и стабилизации.

Ключевые слова: экстрагирование, антоцианы, глицерин, натуральные красители.

\section{Введение}

Для окраски продуктов питания используют синтетические и натуральные красители. Синтетические красители имеют устойчивую яркую окраску, легки в использовании, но могут вызывать аллергические реакции и оказывать другое патологическое воздействие на организм человека. Поэтому окраска продуктов доступными, дешевыми и нетоксичными натуральными красителями является актуальной задачей в пищевой промышленности [1].

Натуральные антоциановые красители (АЦ) содержатся в растительном сырье в виде антоциангликозидов, которые хорошо растворимы в воде [2]. Ниже представлено строение антоциан-3-гликозида в форме катиона флавилия, содержащего от трех до шести гидроксильных групп ( $\left.\mathrm{R}_{1-7}\right)$, которые могут быть метилированы. В темных сортах ягод преобладают АЦ со структурой цианидина и дельфинидина, у которых две или три гидроксильные группы находятся у соседних атомов углерода в ароматическом ядре (структура пирокатехина и пирогаллола):<smiles>[R4]c1cc(-c2[o+]c3cc([R])c([R])c([R4])c3cc2OC)cc([R])c1[R4]</smiles>

Антоциан-3-гликозид<smiles></smiles>

Цианидин<smiles>Oc1cc(O)c2cc(O)c(-c3cc(O)c(O)c(O)c3)[o+]c2c1</smiles>

Дельфинидин
Переверткина Инна Васильевна - доцент, кандидат химических наук, e-mail: pinna58@ mail.ru Волков Алексей Дмитриевич - соискатель Титова Надежда Николаевна - соискатель Болотов Владимир Михайлович - профессор кафедры химии и химической технологии органических соединений и переработки полимеров, доктор технических наук
В растениях антоциангликозиды являются составной частью сложной биохимической системы. При экстрагировании они могут терять свою стабильность из-за гидролиза гликозидов с образованием плохо растворимых в воде антоцианидинов или протекания других окислительно-восстановительных процессов [3]. Поэтому при выделении АЦ приходится решать задачи по их стабилизации и концентрированию.

\footnotetext{
* Автор, с которым следует вести переписку.
} 
Предложенный нами ранее водно-глицериновый растворитель для экстракции антоциановых пигментов из высушенных выжимок темных сортов ягод $[4,5]$ позволил увеличить концентрацию АЦ и уменьшить содержание воды в экстракте, количество которой часто жестко регламентируется технологическими параметрами (например, при производстве леденцовой карамели). В настоящей работе с целью оптимизации условий экстрагирования АЦ из растительного сырья проведено исследование влияния на их степень извлечения и стабильность следующих параметров: сырья, растворителя, рН среды, температуры и времени. В качестве сырья использовали высушенные и измельченные выжимки ягод черноплодной рябины (Аronia Melanocarpa) и темного сорта винограда (Vitis labrusca $\times$ V. vinifera), которые, будучи отходами сокового производства, доступны и дешевы. В качестве экстрагента изучены вода, этанол, глицерин и водноглицериновые смеси. Выбор растворителей обусловлен возможностью их использования в пищевой промышленности.

\section{Экспериментальная часть и обсуждение результатов}

Проведена экстракция АЦ из высушенных выжимок ягод черноплодной рябины водным раствором $\mathrm{HCl}$ с массовой долей 1\% (I), этиловым спиртом (II), смесью воды и глицерина, взятых в массовом соотношении $1: 1$, содержащей $\mathrm{HCl}$ с массовой долей $1 \%$ (III) и в ее отсутствие (IV). Измельченное сырье обрабатывали экстрагентом из расчета $10 \mathrm{~cm}^{3}$ растворителя на 1 г сырья при $70{ }^{\circ} \mathrm{C}$ в течение 1 ч. Концентрацию красителя определяли фотоэлектроколориметрическим методом ( $\lambda=490$ нм, кювета 10 мм) $[1,3]$.

Результаты эксперимента представлены на рисунке 1. В сравнении с водой и этанолом водноглицериновый растворитель увеличивает экстракцию АЦ из рябины в 2 раза. Это объясняется способностью трехатомного спирта (глицерина) сольватировать полифенольные молекулы АЦ (со структурой пирокатехина и пирогаллола) за счет образования хелатных комплексов посредством водородной связи [5]. У молекул воды и этанола такой возможности нет. Как видно из рисунка 1, подкисление водноглицериновой смеси соляной кислотой (III) на эффективность экстракции АЦ существенного влияния не оказывает.

Изучение термической стойкости АЦ осуществляли термостатированием полученных экстрактов при $80{ }^{\circ} \mathrm{C}$ (рис. 2), а также их водных растворов, приготовленных разбавлением в соотношении $1: 100$ с подкислением концентрированной соляной кислотой до $\mathrm{pH}=0,6$, при $70,80,95^{\circ} \mathrm{C}$ (рис. $3 a, 6$, в) в течение 2 ч. Изменение окраски контролировали измерением оптической плотности растворов через каждые 30 мин. Как видно на рисунках 2 и 3, подкисление растворов приводит к более резкому уменьшению содержания АЦ при длительном нагревании. Это происходит в результате гидролиза антоциангликозидов до антоцианидинов и выпадения последних в осадок. В результате через 2 ч при $70{ }^{\circ} \mathrm{C}$ интенсивность окраски разбавленных растворов уменьшается на 3-15\%, при $80{ }^{\circ} \mathrm{C}$ - на $25-35 \%$, при $95{ }^{\circ} \mathrm{C}$ - на 60-80\%. Для предотвращения гидролиза экстракцию следует проводить безкислотным растворителем, а добавление кислоты, необходимое для более полного перевода АЦ в окрашенную форму, можно осуществлять непосредственно при окраске продуктов, когда нагревание кратковременно.

На рисунке 4 представлены результаты исследования влияния рН среды на интенсивность окраски разбавленных водных растворов, содержащих равное количество экстракта (IV), но разные концентрации соляной или лимонной кислот. Концентрация окрашенной формы антоцианов увеличивается с уменьшением рН среды от 4 до 0,6 почти линейно [3]. Это может быть использовано на практике: изменяя рН продукта, можно регулировать интенсивность его красной окраски.

В смеси вода - глицерин (IV) исследована зависимость степени извлечения АЦ из рябины от времени экстракции и температуры. На рисунке 5 видно, что при $70{ }^{\circ} \mathrm{C}$ большая часть красителя экстрагируется уже за 15 мин, при $80-98{ }^{\circ} \mathrm{C}$ - от 30 мин до 1 ч. При увеличении температуры с 70 до $98{ }^{\circ} \mathrm{C}$ концентрация красителя в экстрактах возрастает. Полученные результаты свидетельствуют о более высокой устойчивости АЦ к экстрагированию при повышенных температурах, чем предполагалось ранее [4].

На рисунках $6 a$, б представлены результаты исследования зависимости концентрации АЦ в экстракте от экстрагента во всем диапазоне составов системы вода - глицерин (всего 11 растворителей) при разных температурах и для разных видов сырья. С увеличением содержания глицерина в смеси концентрация АЦ увеличивается и достигает максимального значения при соотношении компонентов $1: 1$. При дальнейшем увеличении содержания глицерина концентрация АЦ в экстракте падает. Это можно объяснить тем, что глицерин - очень сильно ассоциированная вязкая жидкость. Добавление воды к глицерину 
частично разрушает его ассоциацию и усиливает соватирующую способность. Увеличение температуры экстрагирования с 70 до $98{ }^{\circ} \mathrm{C}$ повышает эффективность экстракции по той же причине.

На концентрацию АЦ также влияют степень измельчения, срок хранения сырья и особенно сильно сорт, место произрастания и степень вызревания ягод. Например, концентрация АЦ в экстрактах, полученных из выжимок темного сорта молдавского винограда (рис. 6 б), в 2 раза больше, чем из выжимок местного винограда [1]. Высокое содержание АЦ в сырье частично нивелирует влияние глицерина на эффективность экстракции АЦ: в сравнении с водой максимальное увеличение концентрации красителя при экстракции водно-глицериновой смесью составляет $30 \%$ (рис. 6 б). При низком содержании АЦ в сырье экстрагирующая роль глицерина в смеси возрастает и позволяет увеличить содержание АЦ в экстракте до 100\% (рис. $6 a$ ).

Увеличить концентрацию АЦ в экстракте также можно, уменьшая количество растворителя в соотношении растворитель : сырье. Как видно из рисунка 7, при уменьшении в 5 раз объема растворителя в расчете на 1 г сырья концентрация АЦ возрастает приблизительно в 3 раза. Использование объема экстрагента менее $5 \mathrm{~cm}^{3}$ нецелесообразно из-за впитывания растворителя сухим сырьем и уменьшения объема экстракта.

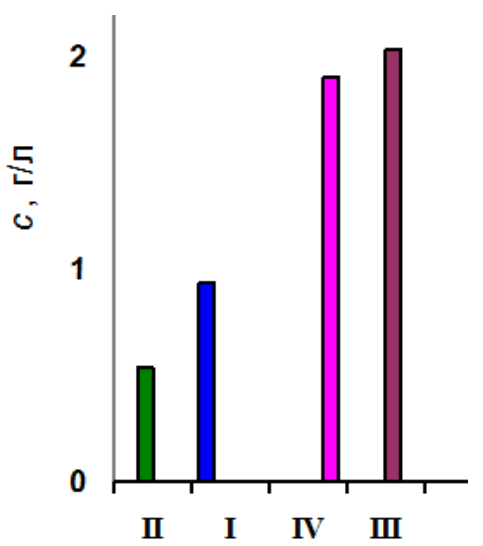

Рис. 1. Зависимость концентрации АЦ (c) в экстрактах черноплодной рябины от состава экстрагента: I - вода, $1 \% \mathrm{HCl}$; II - этанол; III - вода : глицерин ( $1: 1), 1 \% \mathrm{HCl}$; IV - вода : глицерин (1: 1$)$; при $70{ }^{\circ} \mathrm{C}$

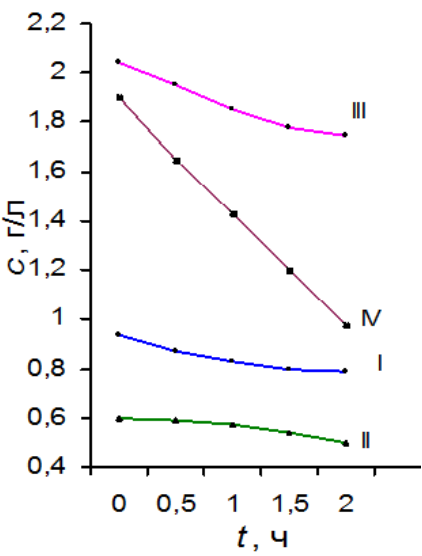

Рис. 2. Зависимость концентрации АЦ (c) в экстрактах черноплодной рябины (I -IV) от времени термостатирования $(t)$ при $80{ }^{\circ} \mathrm{C}$

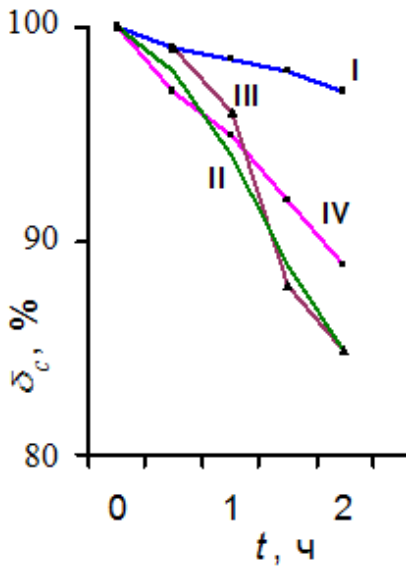

a

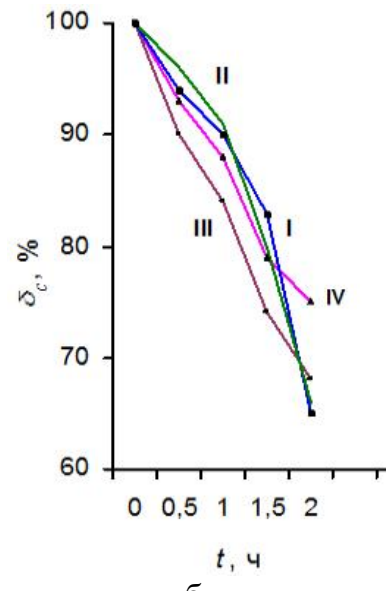

6

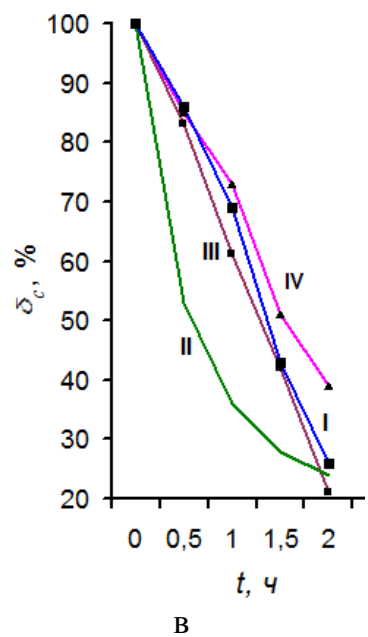

B

Рис. 3. Изменение концентрации АЦ $\left(\delta_{c}\right)$ в разбавленных водных растворах, приготовленных из экстрактов черноплодной рябины (I-IV), от времени термостатирования $(t)$ при температурах: $a-70{ }^{\circ} \mathrm{C}$; $\sigma-80{ }^{\circ} \mathrm{C} ; в-98{ }^{\circ} \mathrm{C}$ 


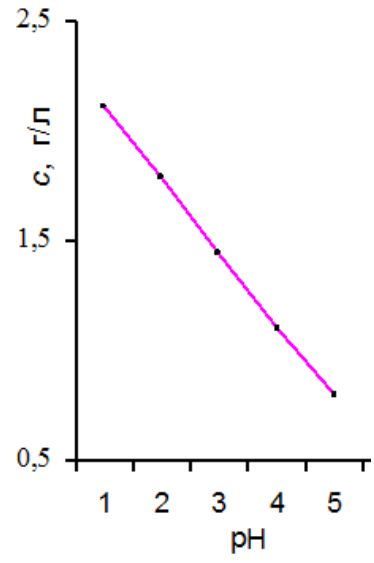

Рис. 4. Зависимость концентрации окрашенной формы АЦ (c) в разбавленных растворах, приготовленных из экстракта черноплодной рябины (IV), от рН среды

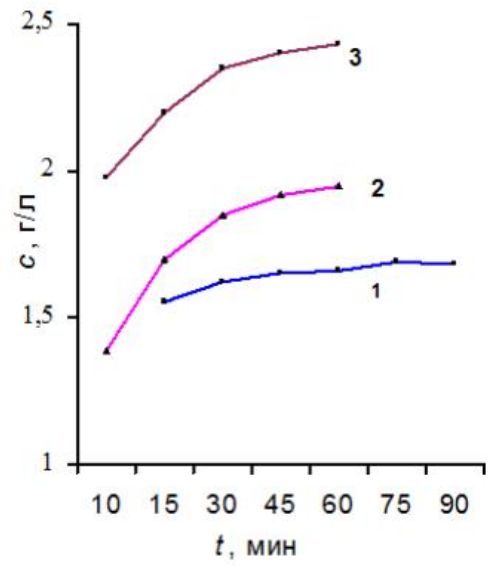

Рис. 5. Зависимость концентрации АЦ (c) в экстракте черноплодной рябины (IV) от времени экстрагирования $(t)$ и температуры: $1-70{ }^{\circ} \mathrm{C}$; $2-80{ }^{\circ} \mathrm{C} ; 3-98^{\circ} \mathrm{C}$

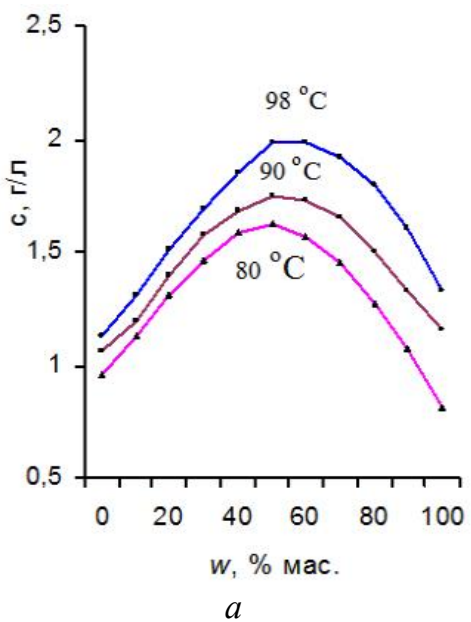

Рис. 6. Зависимость концентрации АЦ (c) в экстрактах от температуры, содержания глицерина в экстракте $(w)$ и сырья: $a$ - черноплодная рябина; $\sigma$ - темный виноград

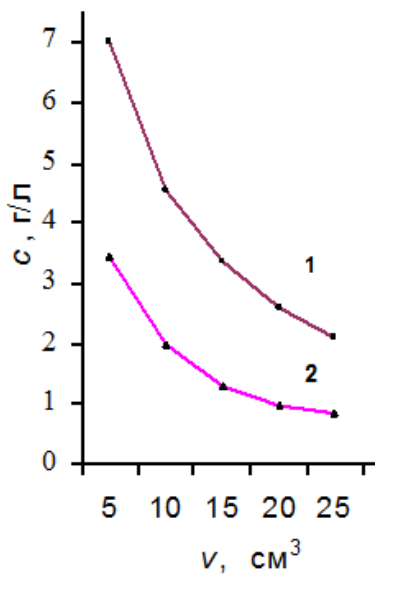

Рис. 7. Зависимость концентрации АЦ (c) в экстрактах от объема экстрагента (IV), используемого для экстракции 1 г сырья (v), при $98{ }^{\circ} \mathrm{C}: 1$ - виноград; 2 - черноплодная рябина

\section{Выводы}

Из анализа результатов проведенного исследования следует, что для получения красного красителя с максимальной концентрацией АЦ из выжимок темных сортов ягод необходимо смешать высушенное и измельченное сырье со смесью воды и глицерина, взятых в массовом соотношении $1: 1$ из расчета 5 см $^{3}$ на 1 г сырья; экстрагирование проводить при 90-98 ${ }^{\circ} \mathrm{C}$ в течение 0,5-1 ч при перемешивании; экстракт отфильтровать от твердой фракции, твердую фракцию отжать.

Предложенный способ прост и позволяет получить краситель с концентрацией красных пигментов, достаточной для практического использования. Краситель следует получать непосредственно перед применением, минуя стадии концентрирования, стабилизации и хранения. Это позволяет исключить присутствие соляной кислоты в экстрагенте (необходимой для подавления роста микроорганизмов в экстракте при хранении), упростить и интенсифицировать процесс экстракции, повысив температуру и сократив время экстрагирования. 


\section{Список литературы}

1. Харламова О.А., Кафка Б.В. Натуральные пищевые красители. М., 1979. 191 с.

2. Таничев С.С. Антоцианы в плодах и овощах. М., 1980. 302 с.

3. Болотов В.М., Нечаев А.П., Сарафанова Л.А. Пищевые красители: классификация, свойства, анализ, применение. СПб., 2008. 204 с.

4. Патент №2426755 (РФ). Способ получения антоцианового красителя из выжимок темных сортов ягод / И.В. Переверкина, Н.С. Колтокова, Н.Н. Титова // БИ. №23, 25.06.2009.

5. Переверкина И.В., Волков А.Д., Болотов В.М. Влияние глицерина на экстрагирование антоциановых пигментов из растительного сырья // Химия растительного сырья. 2011. № 2. С. 187-188.

Поступило в редакичию 30 июня 2013 г.

Perevertkina I.V., Volkov A.D., Titova N.N., Bolotov V.M. OPTIMIZATION OF CONDITIONS FOR ANTHOCYANIN DYES EXTRACTION FROM THE VEGETABLE MATERIALS

Voronezh State University of Engineering Technology, Revolution Av., 19, Voronezh, 394000 (Russia), e-mail:pinna58@mail.ru.

Investigation of the influence of different factors (row material type, solvent type, temperature, $\mathrm{pH}$ and duration of process) on the extraction efficiency was carried out for optimization of the anthocyanin dyes extraction process from vegetable raw materials. The conditions which allow to increase the selectivity of red dyes extraction, simplify and intensify the process of dyes production were found.

To obtain the dye with a maximum pigments concentration from dark berries $1 \mathrm{~g}$ of dried and grinded pomaces were mixed with $5 \mathrm{~cm}^{3}$ of $50 \%$ water solution of glicerol; extraction was carried out at $70-98{ }^{\circ} \mathrm{C}$ for $0,5-1 \mathrm{~h}$ at stirring. The solids were filtered out and squeezed. The liquid dye can be used for colouring foods with high acidity, without the stage of concentration, storage and stabilization.

Keywords: extraction, anthocyanines, glycerin, natural colorants.

\section{References}

1. Kharlamova O.A., Kafka B.V. Natural'nye pishchevye krasiteli. [Natural food colors]. Moscow, 1979, 191 p. (in Russ.).

2. Tanichev S.S. Antotsiany v plodakh i ovoshchakh. [Anthocyanins in fruits and vegetables]. Moscow, 1980, 302 p. (in Russ.).

3. Bolotov V.M., Nechaev A.P., Sarafanova L.A. Pishchevye krasiteli: klassifikatsiia, svoistva, analiz, primenenie. [Food colors: classification, properties, analysis and application]. St. Petersburg, 2008, 204 p. (in Russ.).

4. Patent 2426755 (RU). 2009. (in Russ.).

5. Pereverkina I.V., Volkov A.D., Bolotov V.M. Khimiia rastitel'nogo syr'ia, 2011, no. 2, pp. 187-188. (in Russ.).

\footnotetext{
* Corresponding author.
} 
